\title{
Santiago Basabe Serrano (2011), Jueces sin toga: políticas judiciales y toma de decisiones en el Tribunal Constitucional del Ecuador (1999-2007). Quito: FLACSO Ecuador, 200 pp.
}

\section{JOHN POLGA-HECIMOVICH}

University of Pittsburgh

¿Cuál es el papel de las cortes en la política latinoamericana? En la última década se ha empezado a explorar esta pregunta en la Ciencia Política, aunque falta mucho por desarrollar. En una revisión de la literatura de la disciplina, Kapiszewski y Taylor (2008) hallan que la mayoría de publicaciones sobre las políticas judiciales en América Latina son narrativas históricas con una metodología cualitativa que limita la replicabilidad de los resultados. Según ellos, existe una escasez de investigación cuantitativa que haga explícitos sus métodos y presente la posibilidad de aplicación más allá de los casos particulares. Por otra parte, encuentran que la mayoría de publicaciones se centra en solo cuatro países: Argentina, México, Brasil y Chile. El desafío para la disciplina, entonces, es producir un mejor entendimiento del papel político de las cortes en la región mediante métodos científicos rigurosos, sobre todo en los países menos estudiados.

Jueces sin toga: políticas judiciales y toma de decisiones en el Tribunal Constitucional del Ecuador (1999-2007), de Santiago Basabe, constituye un paso adelante. El libro introduce el concepto de los "jueces sin toga" y desarrolla una teoría contraintuitiva sobre el comportamiento de jueces del Tribunal Constitucional (TC) ecuatoriano, a la vez que cuenta con una metodología cuantitativa innovadora y un enfoque en uno de los casos menos estudiados de la región. Su motivación es sencilla: ¿Qué factores determinan el voto de los jueces de rango mayor en un contexto de alta inestabilidad política en Ecuador? Y específicamente, ¿los magistrados muestran evidencias de votos "sofisticadossinceros" o votos "sofisticados-estratégicos"? La propuesta de Basabe es que los jueces del Tribunal Constitucional ecuatoriano votaban de forma sincera, precisamente por su alta inestabilidad laboral. Esto marca -junto con el trabajo de Agustín Grijalva (2010)la primera incursión en la ciencia política a una explicación del comportamiento judicial en el Ecuador.

Jueces sin toga se centra en el TC, que existió entre 1999 y 2007, y que ha sido remplazado por la Corte Constitucional (CC) actual. El TC/CC es el cuerpo encargado con el poder de revisión judicial constitucional, distinto a los tribunales encargados de realizar juicios sobre asuntos civiles o penales, y por consiguiente es el poder con más influencia en resolver disputas políticas. La corte fue establecida por el artículo 198 de la Constitución ecuatoriana de 1998. Este artículo también estableció que los nueve jueces serían escogidos de nueve ternas por una pluralidad del Congreso: dos ternas presentadas por el mismo Congreso, dos por el Presidente, dos por la Corte Suprema, 
una por los consejos municipales, una por las cámaras de producción y comercio y una por grupos sindicales y organizaciones campesinas. Ya en sus funciones, los magistrados del TC debían permanecer 48 meses. Sin embargo, ningún juez llegó a cumplir con el mandato constitucionalmente previsto, debido a que el tribunal fue reestructurado y los jueces removidos en cuatro ocasiones: marzo del 2003, noviembre del 2004, abril del 2005 y abril del 2007. En este contexto de alta inestabilidad laboral, la propuesta de Basabe de que las votaciones de los jueces no representaban mayores influencias políticas, sino reflejaban sus propias preferencias ideológicas es bastante contraintuitivo y novedosa.

Recurriendo a la racionalidad instrumental, Jueces sin toga supone que el comportamiento de cualquier vocal es un producto de su(s) objetivo(s) principal(es). Para crear su marco teórico utiliza los cuatro objetivos identificados por Baum (1997): (1) influir en la elaboración de políticas públicas; (2) mantenerse en funciones; (3) alcanzar otros cargos dentro o fuera del Poder Judicial, y; (4) afianzar e incrementar los espacios de gestión en el libre ejercicio profesional. Según el objetivo que prima, los jueces pueden ejercer un voto estratégico-sincero que refleja sus preferencias ideológicas puras, o un voto estratégico-sofisticado que refleja la influencia de actores institucionales o individuos ajenos al tribunal. Por su parte, cada uno de los cuatro objetivos (y el tipo de voto que se produce) es una función de dos factores: la independencia-autonomía judicial y la estabilidad institucional.

La primera dimensión es la de la autonomía judicial, y no como Basabe cuidadosamente enfatiza, la independencia judicial. El concepto de independencia judicial encarna autonomía judicial de otros actores institucionales, imparcialidad judicial respecto de las partes de un caso e independencia de las cortes de menor rango de sus superiores jerárquicos. El elemento más estudiado en América Latina y tomado aquí por Basabe es el primero, que se refiere a la toma de decisiones libre de presiones externas de otros poderes del gobierno. La segunda dimensión para determinar los objetivos de los vocales, y por consiguiente su comportamiento, es la estabilidad institucional. Lo que resulta de esta interacción de autonomía y estabilidad es una tipología con cuatro tipos ideales: "jueces profesionales", que quieren influir en las políticas públicas y votan de forma sincera, como en los Estados Unidos o Chile; "jueces funcionales", que quieren alcanzar otros cargos y votan estratégicamente; "jueces oportunistas", que votan estratégicamente para mantenerse en funciones, como en Argentina, Venezuela o México, y; "jueces sin toga", en Ecuador.

A causa de la alta inestabilidad de la corte y la relativa autonomía del TC, Basabe propone que los votos sinceros de los magistrados representa una especie de juego de señal (signaling game), pero no entre los jueces y los políticos, sino entre los jueces y sus potenciales colegas y clientes en su libre ejercicio de la profesión de abogados. Para ellos, la visibilidad de ciertas votaciones es importante para que potenciales clientes los reconozcan y sepan sus tendencias ideológicas. Su lógica es que si solo van a durar pocos años -o meses- en el cargo, es lógico usar la plataforma pública de la corte para revelar sus verdaderas tendencias ideológicas para atraer clientela. En algún sentido es 
paradójico que la misma inestabilidad institucional que impide coaliciones de gobierno de largo plazo y políticas públicas con horizontes largos sea el incentivo principal que moldeó el comportamiento sincero de los jueces del TC.

Basabe somete a prueba su hipótesis y varias hipótesis alternativas por una serie de regresiones logísticas, usando como variable dependiente el contenido ideológico de 529 votos dictados en el TC entre 1999 y 2007 en materia económica, y como variable independiente principal la preferencia ideológica de cada uno de los 30 vocales. La operacionalización de la variable dependiente entonces es una variable dicotómica (izquierda-derecha). En contraste, la operacionalización de la actitud política de los jueces del TC en un Índice de Ubicación Ideológica (IUI) es más complicado y marca, en las palabras de Basabe, "la principal contribución metodológica que este libro ofrece" (Basabe Serrano, 2008: 94). Este índice se construye a raíz del promedio de tres indicadores sobre cada juez (su perspectiva en cuanto a temas económicos y cuestiones laborales, y una ubicación ideológica). Pero porque existen récords de votaciones para los jueces en cortes menores y una autoubicación ideológica presentaría fuertes sesgos, Basabe opta por información de 110 encuestas realizadas por expertos en material jurídico en tres ciudades ecuatorianas. Esta estrategia metodológica es innovadora, pero también conlleva problemas, tanto en su generalización como en la generación de valores sin sesgos. Es difícil creer que las opiniones de los expertos, por ejemplo, no estuviesen coloreadas por la variable dependiente (las votaciones de los jueces en el TC), sobre todo en los casos más antiguos. Una medición basada en entrevistas también presenta dificultades en la replicación y aplicación a casos ajenos al Ecuador. Pero, a pesar de ser imperfecta, es una de las pocas posibles opciones.

Al final, estas pruebas empíricas muestren resultados estadísticamente significativos. Efectivamente, los datos y hechos apoyan el argumento de Basabe de que los vocales del TC eran "jueces sin toga". Un juez de izquierda era más proclive a ejercer un voto en contra de la liberalización económica y un juez de derecha más proclive a ejercer un voto a favor de esta liberalización. Estos resultados y el supuesto central de que el libre ejercicio profesional era más importante para muchos vocales que seguir en sus cargos, encuentran apoyo en el quinto capítulo, que explora las trayectorias profesionales de cada juez. Este capítulo es solo una muestra más del manejo que tiene Basabe sobre el pulso de la política ecuatoriana y la clase político-jurídica ecuatoriana. Pero el manejo de la política ecuatoriana nunca está puesto en duda. Aparte de la imperfección de medición de la variable independiente principal, la teoría también se beneficiaría de pequeños cambios.

La teoría está parcialmente ubicada en la teoría existente y aceptada, sobre todo la cuestión de voto estratégico-sofisticado y voto sincero-sofisticado. Sin embargo, no aprovecha la amplia literatura que formaliza la relación entre las cortes constitucionales y los otros poderes del Estado, y que podría prestar una aplicación más general a las conclusiones. Estas teorizaciones condensan la relación entre las cortes constitucionales y los otros poderes de Estado a juegos de señal (signaling games) o juegos de principalagente (principal-agent games), permitiendo robustas conclusiones teóricas e implicaciones 
empíricas. Jueces sin toga tiene una excelente explicación empírica para el comportamiento de los jueces del TC ecuatoriano, y esta explicación está basada en varios supuestos teóricos. Sin embargo, un mayor nivel de abstracción habría dotado a la teoría de un valor agregado importante, permitiendo no solo una explicación del comportamiento judicial en el Ecuador u otros países, sino una interpretación de interacciones estratégicas de dos o más actores en varios contextos sociopolíticos.

Elementos de la explicación empírica también enfrentan desafíos. Basabe descarta varias hipótesis alternativas, pero pasa por alto la propuesta de Grijalva (2010) sobre el comportamiento de los mismos jueces del TC ecuatoriano. Según Grijalva, existen excepciones a las reglas planteadas por Basabe, sobre todo en casos de materia económica priorizada por el Presidente o el gobierno. Debido a los altos costos de monitoreo y seguimiento de las decisiones judiciales, hay una división fundamental entre casos "políticos" visibles y casos no políticos. En aquellas instancias de votaciones públicas e importantes, los jueces votan de forma estratégica porque quieren evitar posibles sanciones y permanecer en sus cargos. En este sentido, el comportamiento de los jueces sigue una estrategia pura -sus decisiones están en parte predeterminadas por la visibilidad del caso-, pero condicional (ni Basabe ni Grijalva consideran el posible empleo de estrategias mixtas).

La diferencia fundamental entre las interpretaciones de Basabe y Grijalva se encuentra en su caracterización de los objetivos primordiales de los magistrados. Para Basabe, la alta inestabilidad laboral hace que los jueces estén pensando más en el ejercicio libre que en permanecer en sus cargos, mientras Grijalva asume que a pesar de la inestabilidad, priman los objetivos de evitar el juicio político y lograr el renombramiento -como sucedió con René de la Torre, tres veces elegido al TC, u Oswaldo Cevallos, Hernán Ribadeneira, Milton Burbano y Carlos Soria, cada uno elegido dos veces al TC. La explicación verdadera probablemente se ubica en algún punto intermedio; el comportamiento de los jueces está dirigido por una combinación de los cuatro factores citados por Baum (1997). Además, es probable que algunos jueces estén guiados más por una lógica que otra.

Cualquiera sea la mejor explicación para el comportamiento judicial en contextos de alta inestabilidad laboral, una de las lecciones más importantes que Jueces sin toga destaca es que las características del diseño institucional y el grado de estabilidad de los actores influyen en la toma de decisiones de los vocales. Indudablemente, las repetidas remociones de jueces del TC y otras cortes ecuatorianas influyeron en el comportamiento de los magistrados al momento de ejercer su voto. La descripción de la interacción del poder judicial y el ejecutivo, y la recolección y sistematización de datos son excelentes pasos para entender el comportamiento de los jueces en el país y pueden servir como modelo para aquellos que se han embarcados en investigaciones parecidas en países menos estudiados. Basabe muestra que es posible hacer una investigación científica de la política en un contexto de datos escasos o no sistematizados. Además, la ágil explicación de Basabe y propuesta conceptual de "jueces sin toga" simultáneamente cambian y fortalecen la teoría aceptada sobre el comportamiento judicial, y permiten una aplicación a varios sistemas políticos latinoamericanos. 


\section{REFERENCIAS}

Baum, Lawrence. 1997. The Puzzle of Judicial Behavior. Ann Arbor: University of Michigan Press.

Grijalva, Agustín. 2010. Courts and Political Parties: The Politics of Constitutional Review in Ecuador. Saarbrücken, Germany: VDM Verlag Dr. Müller.

Kapiszewski, Diana, and Matthew M. Taylor. 2008. “Doing Courts Justice? Studying Judicial Politics in Latin America." Perspectives on Politics 6 (4): 741-67.

John Polga-Hecimovich es candidato a Doctor en Política Comparada de la Universidad de Pittsburgh, y tiene una Maestría en Estudios Latinoamericanos por la Universidad Andina Simón Bolívar del Ecuador. Sus intereses de investigación incluyen la burocracia, la nacionalización de los partidos políticos y la inestabilidad política, con un enfoque en América Latina. E-mail: jpolga@gmail.com 